\section{hio \\ DENTAL MEDICINE}

\title{
Unilateral buccal space masses: a case series
}

Mathangi Kumar ${ }^{1}$, Adarsh Kudva², Ravindranath Vineetha ${ }^{1}$, Monica Solomon ${ }^{3}$

1) Department of Oral Medicine and Radiology, Manipal College of Dental Sciences, Manipal, Manipal Academy of Higher Education, Manipal, Karnataka, India

2) Department of Oral and Maxillofacial Surgery, Manipal College of Dental Sciences, Manipal, Manipal Academy of Higher Education, Manipal, Karnataka, India

3) Department of Oral Pathology and Microbiology, Manipal College of Dental Sciences, Manipal, Manipal Academy of Higher Education, Manipal, Karnataka, India

DOI: $10.15386 / \mathrm{mpr}-1427$

Manuscript received: 23.07.2019

Received in revised form: 05.12.2019

Accepted: 06.01.2020

Address for correspondence:

adarsh.kudva@manipal.edu

This work is licensed under a Creative Commons Attribution-NonCommercialNoDerivatives 4.0 International License

\begin{abstract}
The head and neck region consists of several potential tissue spaces that are formed by the fascial layer. The buccal space is an area of anatomic significance due to its small size and distribution of adipose tissue. Unilateral buccal space masses often pose a diagnostic challenge owing to the diversity of tissues in the area. Here, we report four such cases of buccal space masses arising from different tissues, which presented as unilateral buccal space swelling. This report also highlights the various causes and the differential diagnoses of unilateral buccal space masses.
\end{abstract}

Keywords: unilateral facial swelling, differential diagnosis, neoplasm, surgical treatment, benign tumor

\section{Introduction}

The head and neck region consists of several potential spaces, which are formed by the fascial layer. The buccal space is one such area of anatomic significance that is considered to be the "overlooked space" owing to its small size and distribution of adipose tissue, which is termed as the buccal fat pad [1]. The buccal fat pad is usually larger in children than in adults and is situated between the buccinator and masseter muscles [2]. The anatomical boundaries of the buccal space are formed anteriorly by the muscles of facial expression, posteriorly by the masseter muscle, the mandible and laterally by the superficial layer of the deep cervical fascia. The superior boundary is formed by the zygomatic process of the maxilla and zygomaticus muscles and the inferiorly by the depressor anguli oris muscle and the deep fascia attaching to the mandible [3]. Additionally, the buccal space also communicates freely with the submandibular and the masticatory spaces. This space contains the parotid duct, the accessory parotid tissue, the facial artery and vein, lymphatic channels, minor salivary glands and also the buccal nerve which is a branch of mandibular nerve and the buccal branch of the facial nerve [1]. Thus, the wide range of tissues within the buccal space lends itself to a variety of lesions that could occur within this region [4].

Meta-analysis results suggest that the most common pathology of the buccal space are salivary gland tumors, especially pleomorphic adenoma[1]. Patients with buccal space masses usually present with a cheek mass or swelling that may be readily visible and clinically palpable. In this case series, we present four cases with unilateral buccal space masses due to various pathologies arising from structures nearby and within the buccal space and also emphasize the differential diagnoses of unilateral buccal space masses. In accordance to the PROCESS guidelines proposed by Agha RA et al.; this report is a retrospective case series, single centre, non-consecutive cases reported in tertiary care academic setting between 2014 to 2019 [5]. 


\section{Case series}

\section{Case 1}

A 50-year-old healthy female reported to the Department of Oral Medicine with a complaint of a painful nodular swelling in the right cheek region of sixyear duration. The swelling was painless, had gradually increased in size, and had been painful since the last seven days. There was no history of preceding trauma and no associated pus discharge. On extraoral examination, there was a mild diffuse swelling on the right cheek area, and a well-circumscribed nodule (approx. $2 \times 2 \mathrm{~cm}$ ) was palpable with normal overlying skin. The nodule was freely mobile, firm but slippery and severely tender on palpation. The lesion was extra oral in location, and intraoral examination was not remarkable. Contrastenhanced computed tomography (CECT) showed a mildly enhancing lesion in the right buccal space with areas of calcified specks at the periphery (Figure 1). Surgical excision of the lesion was performed, and the mass was well encapsulated and removed from the right buccal space (Figure 2). Histopathological examination of the lesion comprised of highly vascular connective tissue stroma with irregular vascular spaces lined by endothelial cells. The lumen was filled with RBC's supported by delicate to dense collagen fibers and these features were suggestive of capillary hemangioma with phlebolith.

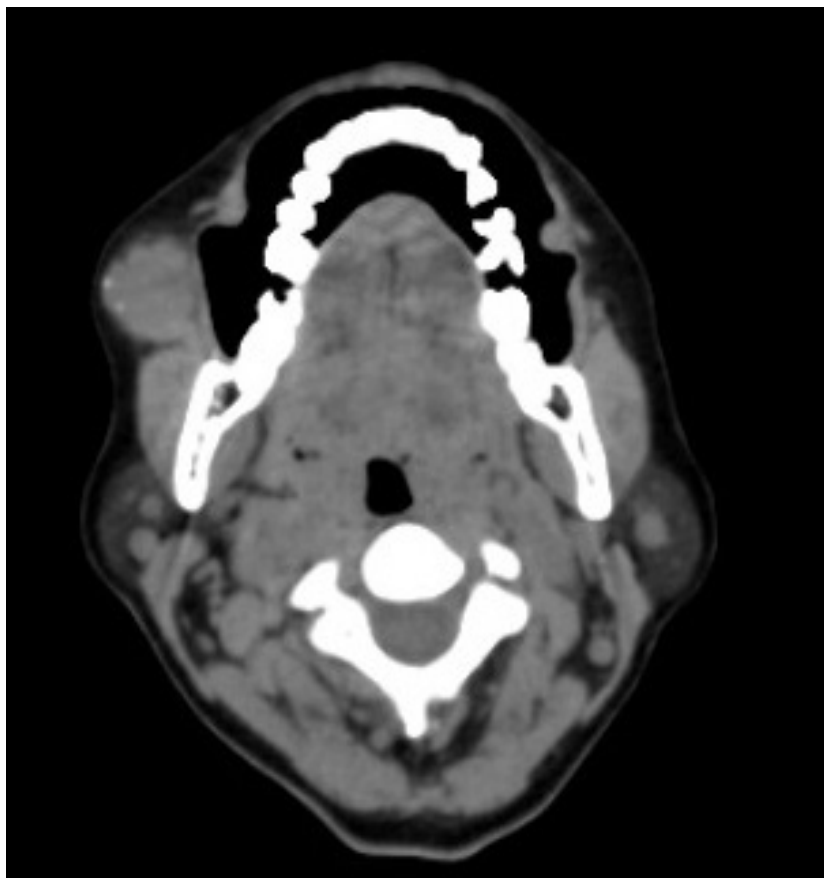

Figure 1. Contrast enhanced computed tomographic axial section image showing mildly enhancing lesion in the right buccal space with areas of calcified specks in the periphery.

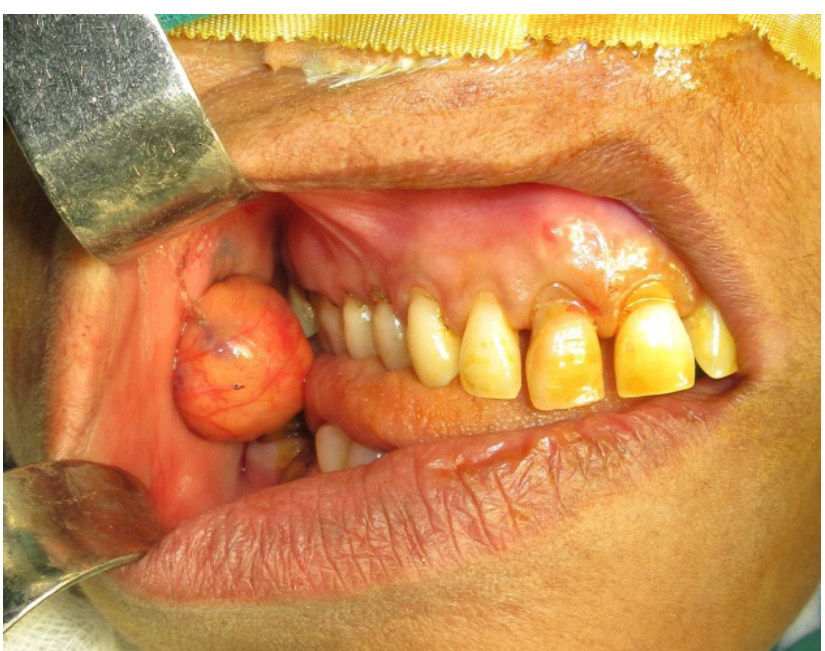

Figure 2. Intra-operative photograph showing the wellencapsulated lesion that was removed from the right buccal space.

\section{Case 2}

A 37-year-old healthy male reported with a complaint of a right cheek swelling of eight-year duration. The swelling was nonprogressive and asymptomatic. On examination, the swelling was well circumscribed, freely mobile, and soft to firm on palpation. The intraoral mucosa was completely normal, and the swelling was within the substance of the buccal mucosa. Ultrasonography of the region evidenced mixed echogenicity with thin internal septae measuring $3.0 \times 0.8 \mathrm{~cm}$. Excisional biopsy was performed, and histopathological features were suggestive of lipoma.

\section{Case 3}

A 36-year-old female reported with a complaint of having noticed a painless non-progressive left cheek swelling of two months duration. There was no history of trauma to the region, and the medical history was non-contributory. On examination, there was a wellcircumscribed movable swelling palpable on the left buccal mucosa. Ultrasonography revealed a hypoechoic lesion measuring $10 \times 7 \mathrm{~mm}$ with peripheral vascularity and minimal central vascularity. CECT imaging showed a heterogeneously enhancing lesion suggestive of a benign salivary gland tumor. Surgical enucleation of the lesion was performed, and the histopathological features of the excised lesion was suggestive of pleomorphic adenoma (Figure 3). 


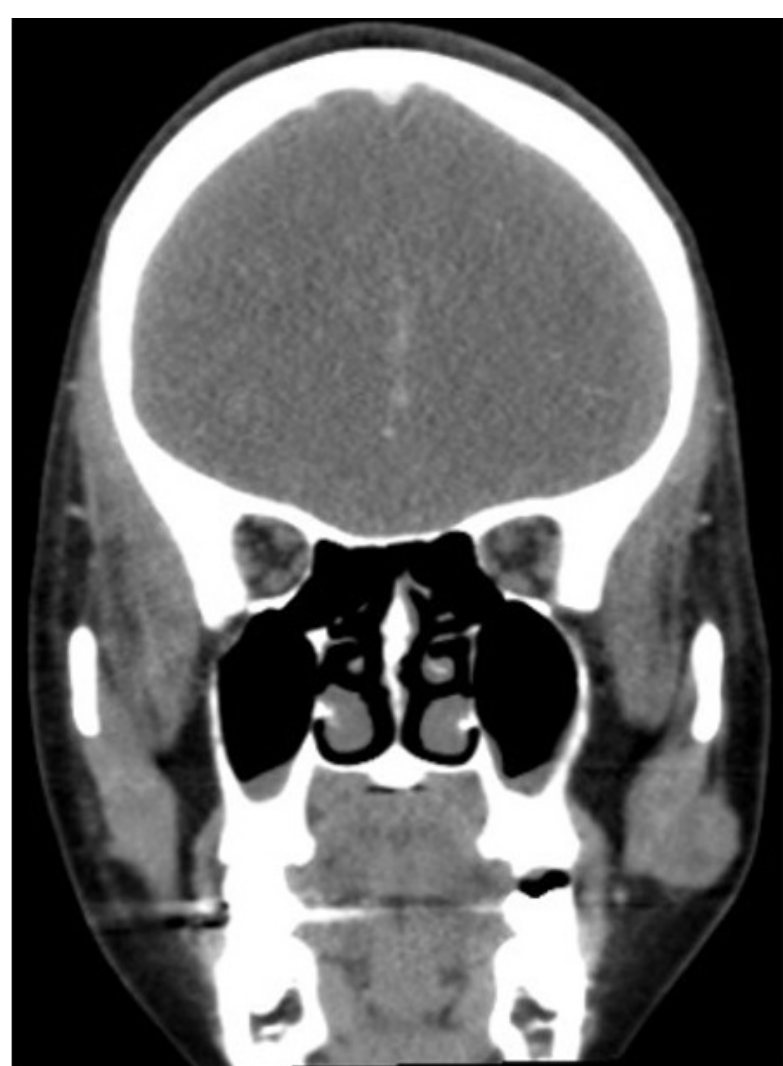

Figure 3. Contrast enhanced computed tomographic coronal image showing heterogeneously enhancing lesion in the left buccal space abutting masseter muscle.

\section{Case 4}

A 41-year-old otherwise healthy female reported with a complaint of a painless swelling of the right cheek region since two months. The mass was in a submucosal location and freely mobile. Histopathological examination of the excised lesion showed plump spindle-shaped cells with elongated nuclei arranged in interlacing fascicles with vascular channels. Immunohistochemical analysis showed a diffuse strong cytoplasmic expression of smooth muscle actin (SMA) and absence of nuclear expression of p63. Thus, the final diagnosis for the case was a solitary myofibroma of the left buccal space.

Thus, these cases represent benign lesions from various tissues of origin with a common clinical presentation as a unilateral buccal space mass. All these cases were advised regular follow up every three months for one-year period. None of these patients reported any recurrence till date.

\section{Discussion}

A wide range of soft tissue lesions may present as submucosal masses. Differential diagnoses for unilateral buccal space swellings should be considered taking into account - the age of the patient, onset, and progression of the swelling. Also, clinical examination may provide valuable clues in identifying the pathology with features like appearance, consistency of the lesion to the surrounding structures. Common lesions causing unilateral buccal space swellings are classified based on tissue of origin and presented in Table I.

Table I. Common lesions presenting as unilateral buccal space swellings classified according to the tissue of origin.

\begin{tabular}{|c|c|c|}
\hline Tissue of origin & Condition & Differentiating clinical clues \\
\hline Odontogenic source & $\begin{array}{l}\text { Spread of odontogenic infection to the buccal space, } \\
\text { cellulitis }\end{array}$ & $\begin{array}{l}\text { Decayed tooth, acute onset of pain, response to } \\
\text { antibiotics and anti-inflammatory drugs }\end{array}$ \\
\hline Blood vessel & Hemangioma, AV malformation & $\begin{array}{l}\text { Colour may be red/bluish/brownish } \\
\text { Surface may be irregular/smooth } \\
\text { Pulsitality/bruits may be felt }\end{array}$ \\
\hline Nerve tissue & Neuroma, Neurofibroma & $\begin{array}{l}\text { History of trauma to the site, firm nodule that is } \\
\text { occasionally tender on palpation }\end{array}$ \\
\hline Adipose tissue & Lipoma, liposarcoma & Soft, mobile asymptomatic mass \\
\hline Salivary glands & $\begin{array}{l}\text { Sialolithiasis of the Stenson's duct, Sialadenitis } \\
\text { Tumors: Pleomorphic adenoma, acinic cell carcinoma, } \\
\text { adenoid cystic carcinoma, mucoepidermoid carcinoma }\end{array}$ & $\begin{array}{l}\text { Painful swelling; acute onset; signs of infection } \\
\text { Painless/painful swelling } \\
\text { Usually chronic }\end{array}$ \\
\hline Lymphoid tissue & $\begin{array}{l}\text { Reactive lymphadenopathy of the buccal/facial/ } \\
\text { intraparotid nodes } \\
\text { Metastatic lymphadenopathy } \\
\text { Lymphomas } \\
\text { Lymphangioma } \\
\text { Calcified lymph node }\end{array}$ & Painless asymptomatic swelling \\
\hline Muscle tissue & $\begin{array}{l}\text { Rhabdomyoma } \\
\text { Rhabdomyosarcoma }\end{array}$ & $\begin{array}{l}\text { Asymptomatic smooth, well circumscribed, mobile } \\
\text { mass }\end{array}$ \\
\hline Other & $\begin{array}{l}\text { Foreign body granuloma } \\
\text { Kimura disease } \\
\text { Solitary fibrous tumor } \\
\text { Traumatic herniation of buccal fat pad }\end{array}$ & $\begin{array}{l}\text { History of trauma or previous surgery } \\
\text { Enlarged lymph node } \\
\text { Painless, slow-growing mass } \\
\text { History of trauma }\end{array}$ \\
\hline
\end{tabular}


Lipoma and hemangioma are the most common benign lesions to affect the oral cavity [6].

Reports suggest that the most common lesions of the buccal space are of vascular and salivary gland origin. Metastatic buccal lymph nodes due to squamous cell carcinoma could also present as masses in the buccal space [3].

Unilateral swellings of the buccal mucosa might be due to various aetiologies: infections, inflammation, benign lesions, or malignant neoplastic conditions. The most common cause of acute unilateral swelling is the spread of odontogenic infections to the buccal space. Tumors of muscular origin are also a consideration due to close approximation of masticatory muscles. Lesions arising in the buccal space may be de novo or may be due to the spread of lesions from the adjacent sites [1]. Also, there are rare reports of collision lesions occurring in the buccal space where two different pathological entities co-exist and present as a single lesion [7].

Capillary hemangioma is an unusual benign soft tissue tumor of the oral cavity. Intraoral lesions account for about $0.5-1.0 \%$ of all intraoral neoplasms with female predilection in second to third decades. A study on 31 cases of intraoral capillary hemangioma showed that buccal mucosa (45.2\%) was the most commonly affected site followed by the tongue (35.5\%). They usually present as a painless, sessile or pedunculated, smooth or lobulated mass with varying sizes. Phlebolith are calcified intravascular thrombi, which are formed due to stagnation of blood, and they are commonly associated with cavernous hemangiomas [8].

Lipoma is a benign tumor of the adipose tissue, and its occurrence is uncommon in the oral cavity.

They present as a small, well-circumscribed mass on the buccal mucosa and tongue. The lesion is usually asymptomatic and has a smooth surface with a sessile or a pedunculated base. They are treated by simple surgical excision, and they do not show recurrence [9].

Salivary gland neoplasms present as painless slowgrowing masses. Pleomorphic adenoma is the most common benign salivary gland tumor. The palate is the most common intraoral site. Minor salivary gland neoplasms account for $<25 \%$ of all salivary gland neoplasms. Tumors of the minor salivary glands may present as well-circumscribed domeshaped swellings with ulceration of the overlying mucosa. These lesions are managed by complete resection of the tumor with adequate margins to avoid recurrence [10].

Myofibromas of the oral cavity are rare benign tumors of myofibroblastic cells affecting individuals of all age groups. Affected individuals are usually below 20 years and the most common site is the mandible. Trauma is an important factor in the causation of myofibromas. They present as a firm mass which is mostly asymptomatic with a pink-red colour. Solitary myofibromas are treated by simple total excision, and they have an excellent prognosis $[11,12]$.
The buccal space is often the most unnoticed due to its restricted size and amount of adipose tissue present within the space. Unilateral buccal space swellings often pose a diagnostic challenge due to the diversity of tissues present within and in the vicinity. Hence, the clinician should be aware about the different pathologies, which could manifest in this space.

\section{References}

1. Seelagan D, Noujaim SE. A pictorial review of the anatomy and common pathology of the buccal space: "The overlooked space.” Appl Radiol. 2007;36:20-28.

2. Iehara T, Tomoyasu C, Nakajima H, Osamura T, Hosoi H. Traumatic herniation of the buccal fat pad. Pediatr Int. 2016;58:613-615.

3. Kim HC, Han MH, Moon MH, Kim JH, Kim IO, Chang KH. $\mathrm{CT}$ and MR imaging of the buccal space: normal anatomy and abnormalities. Korean J Radiol. 2005;6:22-30.

4. Hasan Z, Tan D, Buchanan M, Palme C, Riffat F. Buccal space tumours. Auris Nasus Larynx. 2019;46:160-166.

5. Agha RA, Borrelli MR, Farwana R, Koshy K, Fowler AJ, Orgill DP, et al. The PROCESS 2018 statement: Updating Consensus Preferred Reporting Of CasE Series in Surgery (PROCESS) guidelines. Int J Surg. 2018;60:279-282.

6. Agrawal A, Singh V, Kumar P, Bhagol A, Narwal A, Singh I. Unilateral swelling of cheek. Natl J Maxillofac Surg. 2017;8:157-161.

7. Landa LE, Kathju S, Nepomuceno-Perez MC, Gordon C, Sotereanos GC. Tuberculous granuloma and adenoid cystic carcinoma presenting as a single buccal space mass. J Craniofac Surg. 2002;13:533-537.

8. Kumari VR, Vallabhan CG, Geetha S, Nair MS, Jacob TV. Atypical Presentation of Capillary Hemangioma in Oral Cavity-A Case Report. J Clin Diagnostic Res. 2015;9:ZD26ZD28.

9. Egido-Moreno S, Lozano-Porras AB, Mishra S, AllegueAllegue M, Marí-Roig A, López-López J. Intraoral lipomas: Review of literature and report of two clinical cases. J Clin Exp Dent. 2016;8:e597-e603.

10. Geetha NT, Deepa BV, Umashankara KV, Kithikumar R. Pleomorphic adenoma of minor salivary gland in the cheek. Int J Oral Heal Sci. 2015;5:117-120. doi:10.4103/22316027.178497.

11. Smith M, Reith J, Fitzpatrick S, Cohen DM, Islam MN, Bhattacharyya I. Myofibroma of the oral cavity: an analysis of a large series of 24 new cases and review of the literature. Oral Surg Oral Med Oral Pathol Oral Radiol 2016;122:e169. doi:10.1016/j.oooo.2016.06.066.

12. Narayen V, Ahmed SA, Suri C, Tanveer S. Myofibroma of the gingiva: a rare case report and literature review. Case Rep Dent. $2015 ; 2015 ; 243894$. 